\title{
Traumatic Cervical Spondyloptosis of the Subaxial Cervical Spine: A Case Series with a Literature Review and a New Classification
}

\author{
Jayprakash Vrajlal Modi $^{1}$, Shardul Madhav Soman ${ }^{2}$, Shaival Dalal ${ }^{1}$ \\ ${ }^{1}$ Department of Orthopaedics, B.J. Medical College and Civil Hospital, Ahmedabad, India \\ ${ }^{2}$ Department of Orthopaedics, Government Spine Institute, Ahmedabad, India
}

\begin{abstract}
Study Design: This is a retrospective study on patients with traumatic subaxial cervical spondyloptosis and includes a review of the available literature regarding the management of this injury.

Purpose: This study aimed to assess the biomechanics and varied clinical presentations of this rare but devastating injury.

Overview of Literature: This is a case series of three patients and a review of the available literature on subaxial cervical spondyloptosis. Traumatic cervical spondyloptosis of the subaxial spine is rare, with varied clinical presentations.

Methods: The management of cervical subaxial spondyloptosis represents a challenge to all spine care specialists, and there is a paucity of literature on the best methods for managing this condition. Our experience includes three such patients who visited our tertiary trauma center. This article explains the diverse clinical features of the injury as well as the management of these patients and includes a review of the available literature.

Results: Subaxial cervical spondyloptosis is a devastating injury with diverse clinical features. We present a classification of these fractures based on clinical presentation and magnetic resonance imaging results, which can help in decision-making regarding the management of such patients.

Conclusions: This article may help physicians assess this injury in an evidence-based manner and also elucidates the management strategies available for such patients.
\end{abstract}

Keywords: Decompression; Surgery; Reduction; Neurology

\section{Introduction}

Spondyloptosis is a condition in which there is complete slippage of one vertebral body over the corpus of the adjacent one. It is more common in the lumbar region of the spine [1]. Reported causes of spondyloptosis include congenital vertebral anomalies and an ongoing pathological process in the cervical spine [2]. Patients present with varied neurological statuses, ranging from complete injury to normal intact neurology. Knowledge of this clinical rarity is necessary for the proper management of these patients. Most of the literature related to this condition includes isolated case reports. Three patients with spondyloptosis presented to our tertiary care center over a period of 2 years. The authors have reviewed the available literature and presented it along with the experi-

Received Feb 26, 2016; Revised Apr 2, 2016; Accepted Apr 8, 2016

Corresponding author: Shardul Madhav Soman

Department of Orthopaedics, Government Spine Institute, Ahmedabad, Gujarat 380016, India

Tel: +91-89-80844549, Fax: +91-79-22683421, E-mail: somanshardul@gmail.com 
Table 1. The traumatic subaxial cervical spondyloptosis cases observed at our institute

\begin{tabular}{|c|c|c|c|c|c|c|c|}
\hline No. & $\begin{array}{c}\text { Age }(y r) / \\
\text { Sex }\end{array}$ & $\begin{array}{l}\text { Level of } \\
\text { injury }\end{array}$ & $\begin{array}{l}\text { Neurology on } \\
\text { presentation }\end{array}$ & $\begin{array}{l}\text { Neurology } \\
\text { after surgery }\end{array}$ & $\begin{array}{l}\text { Method of } \\
\text { reduction }\end{array}$ & Surgery & $\begin{array}{l}\text { Complication } \\
\text { during } \\
\text { management }\end{array}$ \\
\hline 1 & 35/Male & C6-7 & ASIA-A & ASIA-A & $\begin{array}{l}\text { Closed reduction } \\
\text { with } 30 \text { pounds } \\
\text { but failed so open } \\
\text { reduction done }\end{array}$ & $\begin{array}{l}\text { Anterior cervical } \\
\text { discectomy and } \\
\text { fusion }\end{array}$ & None \\
\hline 2 & 8/Male & C7-T1 & ASIA-A & - & $\begin{array}{l}\text { Patient treated } \\
\text { conservatively }\end{array}$ & $\begin{array}{l}\text { Patient not } \\
\text { willing }\end{array}$ & $\begin{array}{l}\text { Severe spasticity } \\
\text { with multiple bed } \\
\text { sores and totally } \\
\text { dependant }\end{array}$ \\
\hline 3 & 70/Male & C7-T1 & ASIA-A & - & Closed reduction & $\begin{array}{l}\text { Not operated due } \\
\text { to comorbidities } \\
\text { and high risk }\end{array}$ & $\begin{array}{l}\text { Patient expired due } \\
\text { to the multi-system } \\
\text { failure }\end{array}$ \\
\hline
\end{tabular}

ASIA, American Spinal Injury Association Classification.

ence of these three cases, including the clinical features, biomechanics, and management strategies. Based on the available data in the literature, the authors have proposed a classification of spondyloptosis based on magnetic resonance imaging (MRI) and clinical presentation to assist in decision making.

\section{Materials and Methods}

This study is a case series and a literature review. We studied 11 cases of traumatic cervical spondyloptosis in the subaxial cervical spine (Table 1), and reviewed the literature, which largely consists of isolated case reports. Our three cases were added to this list to help understand the clinical features and formulate management strategies for this rare condition (Table 2) [1-9]. Analysis was carried out in terms of the neurological status on presentation, level involved, method of reduction, whether surgery was performed or not, and the complications faced during the management of each of these cases. Based on presentation, the patients were grouped into two categories. Patients in category 1 had a complete injury (American Spinal Injury Association Classification of spinal cord injury level [ASIA-A]) on presentation, and MRI showed a pinched cord at the level of injury. Patients in category 2 had an incomplete injury or normal neurological status at presentation, and the cord showed almost normal lordotic curve (Fig. 1). All the patients presenting to our tertiary trauma care unit had complete injury (ASIA-A) and were classified as category 1 . One patient presented with an old

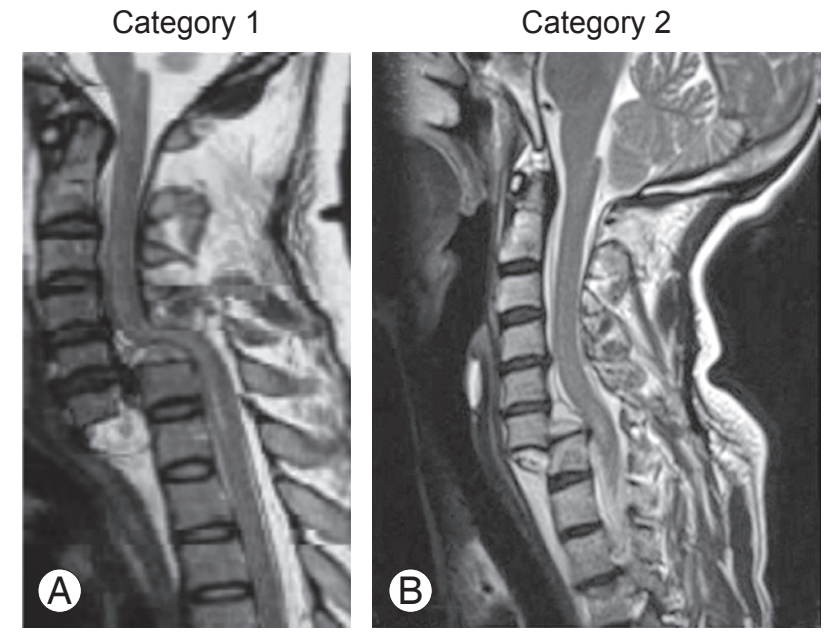

Fig. 1. The new classification based on the status of the spinal cord. (A) Pinced cord suggestive of severe cord damage. (B) Maintainance of the lordotic sagittal alignment of the cord.

injury with in situ fusion and refused any interventions. Another patient achieved reduction with closed methods but could not be operated on due to severe comorbidities. For the third patient, complete reduction could not be achieved by using a closed method, so an open reduction with anterior fusion was carried out. The outcomes for all the patients were poor due to the nature of the injury to the cord and the surrounding structures. The review of literature showed that patients can present with incomplete injuries and even with normal neurology, in which case management has to be more precise. The aim of this study was to shed light on these problems and suggest a valid 


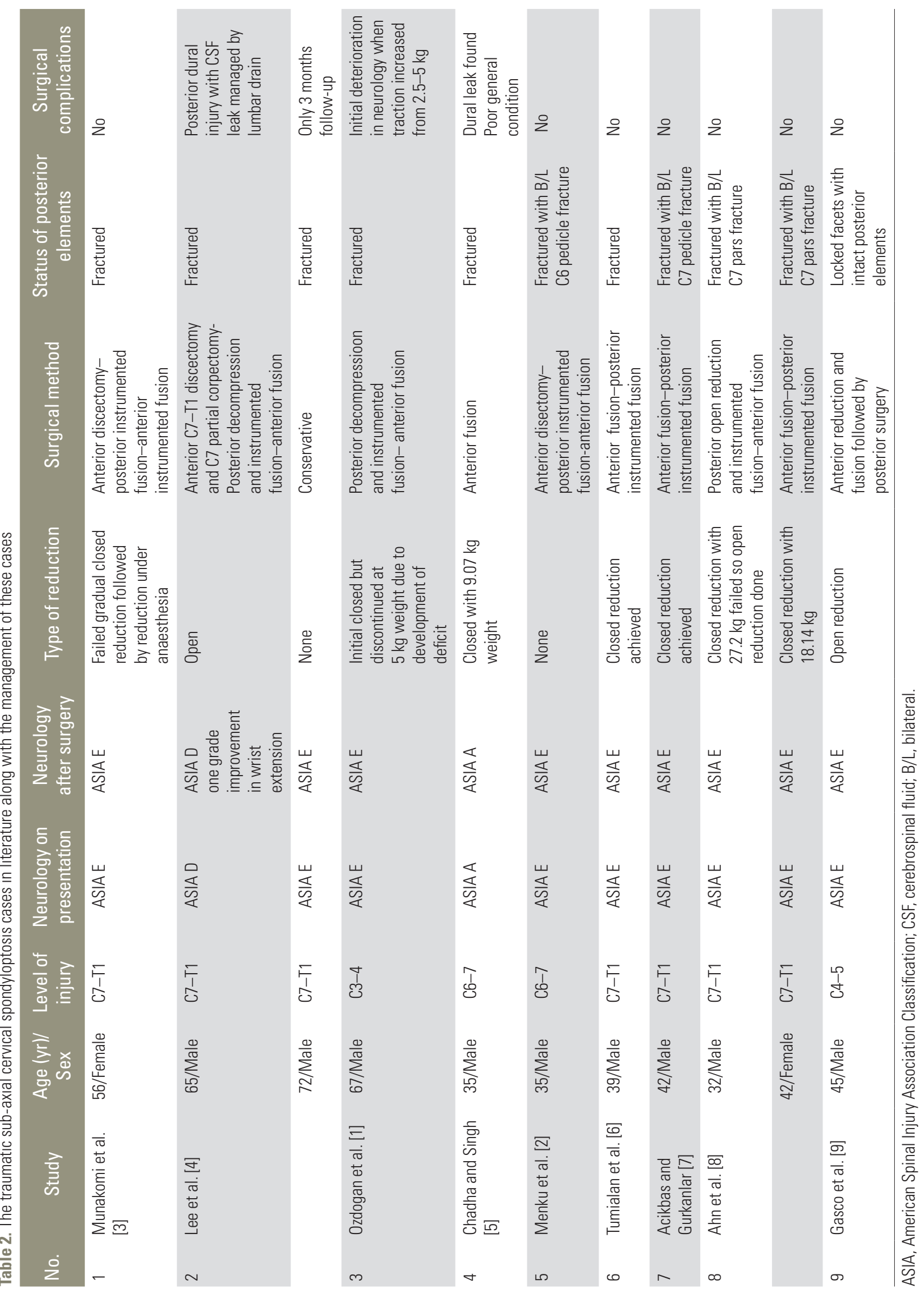


protocol for the management of this condition.

\section{Results}

On the basis of the 11 cases from the literature and our experience of three cases, we obtained the following results.

The subaxial cervical spine C7-T1 was the most common location of spondyloptosis $(n=9 / 14)$. Though the injury could be seen in various age groups ( $8-70$ years), it was most common in middle-aged people (mean age, 45 years) and in males, with road traffic accidents being the most common cause because of the nature of force required for this injury to occur. Four patients were classified as category 1 and ten were classified as category 2 . As expected, all category 1 patients had a complete injury (ASIA-A), and category 2 patients showed incomplete or normal neurological status on presentation. Various methods of management were employed, which included initial closed reduction followed by various methods to stabilize the spine. Of the eight patients in which closed reduction was attempted, only four were successfully reduced; three required conversion to open surgery, and one patient developed neurological deficit on traction so the intervention was discontinued. Three patients were managed conservatively, and in the other three patients no attempt at closed reduction was made (Fig. 2). The methods of surgery used included conservative $(n=3)$, anterior surgery only $(n=2)$, anterior discectomy followed by posterior instrumented fusion followed by anterior fusion $(\mathrm{n}=3)$, anterior fusion followed by posterior instrumented fusion $(n=4)$, and posterior reduction and instrumented fusion followed by anterior fusion $(\mathrm{n}=2)$. The neurological outcomes remained the same as before the interventions irrespective of the methods of reduction and surgery used. There were various complications associated with the management of these patients (Table 3, Fig. 3), including two reports of intraoperative dural tear that were managed uneventfully with lumbar drain. Patients in category 1 had a worse prognosis with no improvements in neurological status, and complications associated with spinal cord injury, such as severe spasticity and bed sores,

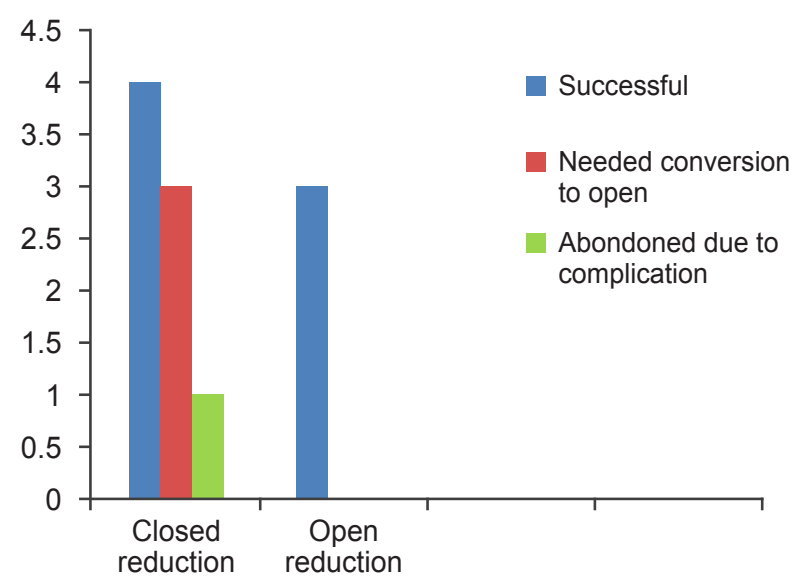

Fig. 2. The reduction methods used in the management of these patients.

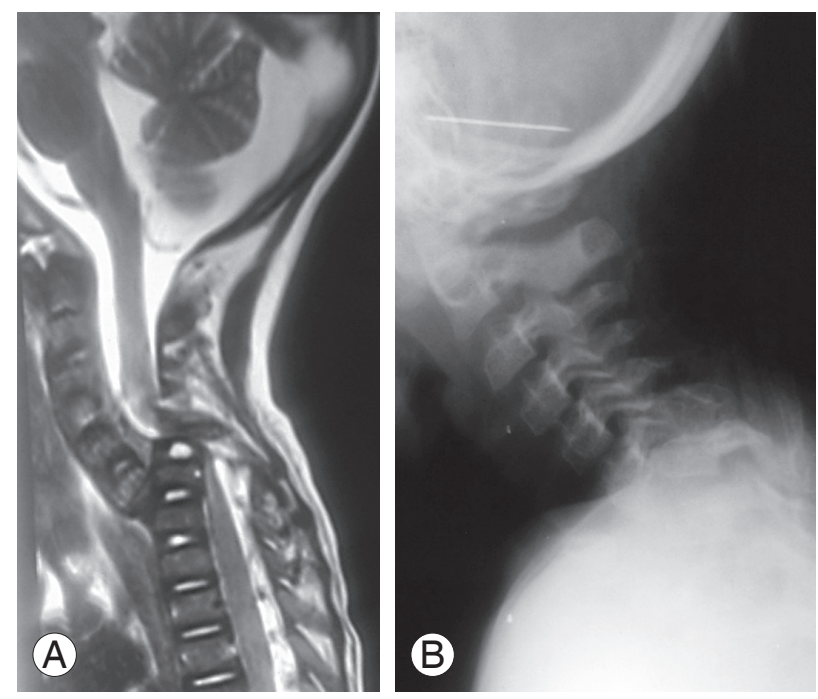

Fig. 3. (A, B) Severe sagittal mal-alignment complication seen in a patient that presented to us after a delay in treatment.

Table 3. Enumerates the complications observed in the literature in the management of these cases

\section{Complications associated with management}

Neurological deterioration during reduction

Dural injury

Vertebral artery injury

Complications associated with spinal cord injury like bed sores, DVT, infections, functional dependence, mortality

Unacceptable alignment due to malunion due neglected cases (Fig. 2)

DVT, deep vein thrombosis 
and comorbidities that led to mortality in two out of four patients within six months of injury.

\section{Biomechanics and condition of the spinal cord on MRI}

In the subaxial cervical spine, the ligamentous structures provide a check of hypermobility during normal motion. For example, the anterior longitudinal ligament and ventral annulus become taut during extension, whereas the posterior column ligamentous structures act as a tension band during flexion. Compressive loads are resisted by the vertebral bodies, intervertebral discs, and facet joints. Pure tensile loads are resisted by the annulus, interspinous ligament, ligamentum flavum, and facet capsules. Flexion is resisted by the interspinous ligaments, facet capsules, facet joints, anterior longitudinal ligament, and posterior annulus. Extension is also resisted by the bony block of the facet joints. The maximal sagittal plane translation occurring under physiologic loads is $2-2.7 \mathrm{~mm}$ [10].

Cervical spondyloptosis is a type of compressive extension five-stage injury. It involves bilateral vertebral arch fracture with anterior displacement of the full vertebral body. Ligamentous failure occurs at two levels, posteriorly between the suprajacent and fractured vertebra and anteriorly between the fractured vertebra and the subjacent one. In spite of this, the cord is sometimes spared compression or is subjected only to a mild compression due to the spontaneous decompression of the cord by the fractured posterior elements [11]. However, as found in all of our three patients with complete injury (ASIA-A), the cord was found to be severely contused with edema and extensive soft tissue edema in the paraspinal region. This suggested a high degree of trauma. The cord was compressed between the anterior vertebral body of the inferior vertebra and the posterior elements. In addition, the anterior ptosis of the superior vertebral body with the bipedicular fracture carrying the cord anteriorly led to the so-called pincer phenomenon. In the patients with intact neurological status, however, the cord remained in a lordotic position and was not shifted anteriorly along with the superior vertebral body. The fact that this injury has different presentations could thus be explained by the lack of shift or maintenance of the lordotic shape of the cord in category 2 patients (Fig. 1). Gasco et al. [9] showed in a case report that in spite of intact posterior elements, a patient continued to have an intact neurological status with an in situ fusion after eight months of subaxial spondylop- tosis. The cord maintaining its near normal contour seems to be an important factor in the neurological presentation of these patients. Although this study included only a small number of patients, the classification may be a useful method for categorizing and managing these patients. Increasing the number of cases studied will help to assess the validity of this classification.

\section{Discussion}

The majority of cervical injuries occur in the subaxial spine (approximately 65\% of fractures and more than $75 \%$ of all dislocations) [12]. Spondylolisthesis and spondyloptosis of the lumbar spine are well described, but they very rarely occur in the cervical spine. The reported causes of spondyloptosis include an ongoing pathological process of aneurysmal bone cyst, Klippel-Feil syndrome, neurofibromatosis, absent posterior elements, and, importantly, birth trauma. Isolated traumatic spondyloptosis in the cervical spine has been reported sporadically $[11,13]$. However, the reason for this may be not only the rarity of the injury but also the poor outcomes for these patients and a lack of data reporting, especially in developing countries. In tertiary trauma care, one must be familiar with the scientific management of these patients as they present differently, and inappropriate management can be disastrous. In our tertiary trauma care unit we have treated three patients with spondyloptosis out of a total of 107 patients with cervical spinal injuries over a period of two years; this suggests that the injury may be much more common than is reported. There is a lack of literature on the management of these injuries; most are sporadic case reports. A literature study of 1,200 cases by the American Association of Neurological Surgeons reported only level III evidence on the use of closed reduction as a tool to reduce fracture dislocation in patients with cervical dislocation [14]. This study found an overall success rate of traction achieving reduction of $80 \%$ and a permanent neurologic complication rate of $1 \%$, with a $2 \%$ rate of transient neurologic deterioration. It found that the causes of deterioration were not limited to disk herniation. Such causes also included overdistraction, spinal cord edema, and a more rostral noncontiguous injury. The authors noted that the number of deteriorations due to disk herniation in awake patients undergoing closed reduction was extremely small. Considering these data even in patients with spondyloptosis, the author recommends an initial trial of closed reduc- 


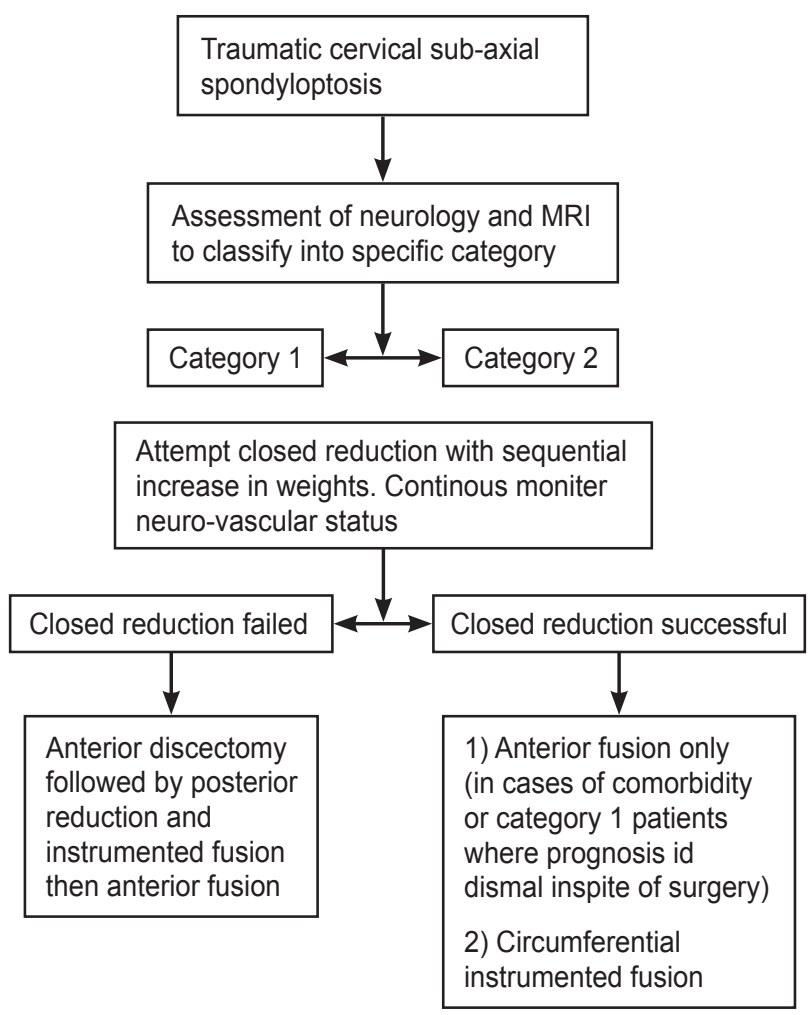

Fig. 4. Flowchart suggested by the authors for the successful management of these patients. MRI, magnetic resonance imaging.

tion by sequential increase in weight with continuous monitoring of neurological status of the patient. However, this should not be attempted, or the attempt should be abandoned, in patients in whom there is a deterioration in neurology or in whom an awake analysis of neurological status is not possible.

For patients in whom closed reduction fails, open reduction can be achieved by either a posterior approach or by an initial anterior discectomy to decompress the cord and to prevent any further compression of the cord while reduction by retropulsion of the disc fragments followed by posterior reduction or an in situ anterior fusion is carried out. The opinion in the literature is divided on how to manage these patients, ranging from conservative care or anterior fusion only, to an anterior discectomy followed by posterior instrumented fusion and again anterior fusion. However, in each of the literature reports, the outcome of the patient did not have any relation to the method of treatment used. Accordingly, in category 1, the outcomes of the patients remained poor due to the pinched cord and severe hemorrhage and edema in the spinal cord, so these patients benefit from a more conservative approach such as an attempt at closed reduction with continuous neurovascular status monitoring and close monitoring of the patient's general condition and vitals, especially respiratory function. These patients can be managed well by anterior fusion surgery only and avoiding prolonged surgery, as seen in one of our patients. In category 2, we recommend an initial MRI scan before reduction is attempted, followed by a controlled attempt at reduction under strict neurovascular monitoring. An attempt should be made to at least partially reduce the dislocation. In case of any deficit observed on sequential increase in weight, the attempt should be aborted and surgery planned. The appropriate surgical methods are controversial, with every approach having pros and cons. However, considering the biomechanics, an initial anterior discectomy followed by a posterior reduction (if not reduced with instrumented fusion) followed an anterior fusion procedure seems to be the most appropriate as it provides the best stability and also prevents any chance of disc compression while the reduction is done in the prone position [15]. In patients in whom complete reduction is achieved, management by anterior discectomy and fusion followed by posterior instrumented fusion can be used (Fig. 4). The most common complication was dural injury with cerebrospinal fluid leakage, which was managed in both cases by standard management. Another complication that should be borne in mind is possible vertebral artery injury, especially while using the posterior approach for reduction.

\section{Conclusions}

Subaxial cervical spondyloptosis is a rare injury with varied clinical presentations. Management of these patients requires the utmost care in terms of methods of reduction of the fracture and subsequent surgical stabilization. Classification of this fracture on the basis of the MRI and clinical presentation is helpful to understand the nature and prognosis of the spinal cord injury and can be useful for the management of these patients.

\section{Conflict of Interest}

No potential conflict of interest relevant to this article was reported.

\section{References}

1. Ozdogan C, Gogusgeren MA, Dosoglu M. Posttrau- 
matic cervical spondyloptosis: case report. Turk J Trauma Emerg Surg 1999;5:46-8.

2. Menku A, Kurtsoy A, Tucer B, Oktem IS, Akdemir H. The surgical management of traumatic C6-C7 spondyloptosis in a patient without neurological deficits. Minim Invasive Neurosurg 2004;47:242-4.

3. Munakomi S, Bhattarai B, Cherian I. Traumatic cervical spondyloptosis in a neurologically stable patient: a therapeutic challenge. Case Rep Crit Care 2015;2015:540919.

4. Lee DG, Hwang SH, Lee CH, Kang DH. Clinical experience of traumatic C7-T1 spondyloptosis. J Korean Neurosurg Soc 2007;41:127-9.

5. Chadha M, Singh AP. Spondyloptosis of C6-C7: a rare case report. Chin J Traumatol 2010;13:377-9.

6. Tumialan LM, Dadashev V, Laborde DV, Gupta SK. Management of traumatic cervical spondyloptosis in a neurologically intact patient: case report. Spine (Phila Pa 1976) 2009;34:E703-8.

7. Acikbas C, Gurkanlar D. Post-traumatic C7-T1 Spondyloptosis in a patient without neurological deficit: a case report. Turk Neurosurg 2010;20:257-60.

8. Ahn TK, Chung YS, Kim MS, Han I. High-grade traumatic spondylolisthesis of C7 on T1 with no neu- rological deficit. Nerve 2015;1:37-9.

9. Gasco J, Dilorenzo DJ, Patterson JT. C4-C5 posttraumatic spondyloptosis with in situ fusion: systematic literature review and case report. Spine (Phila $\mathrm{Pa}$ 1976) 2013;38:E621-5.

10. White AA 3rd, Panjabi MM. Clinical biomechanics of the spine. Philadelphia: JB Lippincott; 1978.

11. Bhojraj SY, Shahane SM. Posttraumatic cervical spondyloptosis at C6-7 with late-onset cord compression: a new clinical entity: case report. J Neurosurg 1992;77:792-4.

12. Watson-Jones $\mathrm{R}$. The results of postural reduction of fractures of the spine. J Bone Joint Surg Am 1938;20: 567-86.

13. Shah KC, Rajshekhar V. Successful management of post-traumatic C7-T1 spondyloptosis with uninstrumented ventral surgery. Surg Neurol 2004;62:431-4.

14. Initial closed reduction of cervical spine fracturedislocation injuries. Neurosurgery 2002;50(3 Suppl):S44-50.

15. Keskin F, Kalkan E, Erdi F. The surgical management of traumatic C6-C7 spondyloptosis. J Korean Neurosurg Soc 2013;53:49-51. 